\title{
The Meta-pragmatic Functions of English Discourse Markers
}

\author{
Xiuling Liu \\ School of Foreign Studies, Xi'an University of Arts and Science, Xi'an Shaanxi, China, 710065
}

Keywords: Meta-pragmatic awareness; Meta-pragmatic functions

\begin{abstract}
Discourse markers are only a small group of words in English, but the study of discourse markers has become an interdisciplinary and interdisciplinary research. This paper holds that discourse markers play a procedural role in the discourse, reveal the meta-pragmatic awareness of language users, and exert a series of meta-pragmatic functions. This paper extends a discussion and makes some conclusions to those meta-pragmatic functions.
\end{abstract}

\section{The Composition, the Names and the Definitions of Discourse Markers}

Although discourse markers are a small group of words, they are prevalent in various languages. Researchers from different races and different countries have discussed them in diverse perspectives. Many scholars have extended wide research on them in the aspects of psychology, philosophy and linguistics, and the research angles have been shifted from the syntactic-pragmatic ones or the semantic-pragmatic ones to the pragmatic-cognitive ones.

Discourse markers are few in English, mainly composed of interjections (well, oh, uh), adverbs (actually, incidentally, frankly), conjunctions ((and, therefore, however, but), phrases (As a consequence, in particular, you know, I mean, therefore), and clauses (according to, I think, I guess). However, since different researchers unfold their research from different angles, this small group of words has different names, such as logic connectors, particles, gambits, discourse operators, discourse markers, discourse signaling devices, pragmatic particles, pragmatic formatives, pragmatic function words, semantic conjuncts, disjunct markers, clue words, extra sentential links, hyperpropositional expressions, conversational routines, prefaces, phatic connectives, etc.. The difference of those terminologies reflects that different researchers undertake their research on this group of words from different angles in different ways, and that discourse markers have various discourse functions. At present, there is no consensus on which terminology can be used to generalize such group. In this paper, the terminology discourse markers is used to summarize them, because "This term appears to be the one with the greatest universality and the least applicability, and it allows us to include a large variety of words under a semantic concept".

Additionally, different scholars give distinct definitions to discourse markers. Among them, Schiffrin, a well-known scholar who studies English discourse markers in depth, argues that discourse markers are "a set of functional, verbal (or non-verbal) tools that provide contextual assistance to ongoing discourses". And Levinson thinks that discourse markers are "undoubtedly the words or phrases that can indicate the relation of a discourse to the preceding discourse in English. Usually they show how the words reflect or continue to discuss certain parts of the former words in very complex ways. Redeker defines discourse markers as "a group of discourse operators that are universally used as coherent language markers in discourse". On the basis of Redeker's definition, Lenk's, the German scholar, concludes the definition of discourse markers that: "Discourse markers are short terms, and in the meta-language level, their pragmatic meanings are used as an indication to the listener on how the speaker attempt to set up an association with the preceding and / or subsequent discourses "

In the study of discourse markers, Blakemore proposed the conceptual meaning and the procedural meaning in discourse. On the one hand, the conceptual components in the language structure assume the propositional meaning of the context and affect the true value of the context in the traditional sense. On the other hand, the procedural elements in the language structure only limit the possibilities of discourse comprehension, providing clues and direction to the understanding of the context and presenting the author's subjective attitude. This paper proposes that discourse 
markers play a role, exactly at the meta-level, mainly in encoding procedures, but not in the propositional meaning of the discourse, which serves to guide or restrict the understanding of the textual propositional meaning. What's more, they are in non-truth condition, namely not affecting the true value of the sentence. In addition, they are mainly able to release the attitude or the intention of the language user on the meaning of sentence proposition, to reflect the author's meta-pragmatic awareness, and to play meta-pragmatic functions.

\section{The Meta-pragmatic Functions of Discourse Markers}

The functions of discourse markers are to reflect the pragmatic consciousness of the language users in the process of using the language, and to show their subjective will, attitude, emotion and aspiration which may be naturally revealed during using the utterance, so as to guide and restrict the understanding of the communicative object on the meaning of discourse proposition. In general, discourse markers have the meta-pragmatic functions in constructing discourses, indicating the intention and emotion of language user, shortening interpersonal distance and regulating the interpersonal relations. In terms of indicating the intention and emotion of language user, the meta-pragmatic function of discourse markers can be further subdivided into several functions, including revealing personal feelings of the speaker, expressing the subjective evaluation of the speaker, showing the way of expressing his or her own speech, and modifying the utterance expression and so on.

Firstly, discourse markers can construct context. In the course of communication, the speaker always tries to make his discourse coherent and fluent, and they always reflect the meta-pragmatic consciousness of organizing and controlling the discourse so as to help the communicating object to understand the whole context better.

Thus, they use discourse markers to inform the listener in advance that they want to start a new topic by providing words as clues such as first, firstly, first of all, at first, in the first place, in the beginning, to begin with, to start with, once upon a time, now, etc. , or to end a topic that has already fully discussed through words such as therefore, thus, finally, eventually, at last, in conclusion, in short, in the end, in a word, in brief, in summary, on the whole, as a result, to sum up, to conclude, etc., or to shift the topic by phrases such as by the way, incidentally, and well, etc., or return to the previous topic by the expression such as you see, you know, any-way, as noted above, as mentioned before, to return to my point, back to the original point, etc. , or to indicate that they want to continue without being interrupted by the words such as well, er, mm, uh , and, etc..

In addition, the language user can use the discourse markers such as and, or, also, meanwhile, at the same time, in the meantime, on the one hand, on the other hand, etc. to indicate the listener that the meaning below the proposition is parallel to that above, use such as but, however, yet, though, although, whereas, nevertheless, nonetheless, despite, in spite of, otherwise, alternately, conversely, in contrast, contrary to, on the contrary, instead of, rather than, in comparison to guide the listeners that there will be a turning point and contrast between the propositional meaning below and the above, use such as moreover, furthermore, likewise, addition-ally, in addition, what's more, besides to prompt the listener that a new information will be provided to explain the previous topic. Moreover, the discourse markers like because, so, since, therefore, accordingly, consequently, as a con-sequence / result, also can be used to indicate the reasons, explain, and make detailed explanations. Therefore, discourse markers play the meta-pragmatic role by clues, and reflect the pragmatic sense of coherence and coherence of the language user's organization at the meta-level of the context. It can prompt and guide the understanding of the discourse and achieve the communication.

Secondly, in addition to indicating the organization and control of language users, discourse markers can also explicitly or implicitly express their feelings or intentions to the propositional meaning in the discourse. Discourse markers can indicate the speaker's emotions, such as hesitation, refusal, compromise, self-confidence and so on. The discourse markers that reflect these meta-pragmatic functions may be adverbs, such as even, anyway, indeed, probably, approximately, likely, perhaps, maybe, actually, specially, certainly, and so on. They can also be phrases such as 
after all, in fact, in particular, in course. What's more, they can even be short sentences such as I guess, I doubt, I suppose, I think, I believe, I regret, I admit, I hope, and so on.

(1) Jack: How about John's exam?

Iris: He failed, I suppose.

This example shows the speaker's hesitant and uncertain emotions.

(2) In fact, in everyday language use, euphemism is ubiquitous.

Here, the phrase in fact indicates the affirmation and emphasis the speaker on the content.

Discourse markers can also show the speaker's compromise and compromise, such as:

(3) Peter is stingy and hair - splitting. Anyway, he is a nice guy.

Different discourse markers can express a variety of emotions, such as:

(4) These jeans are better on me, they are like not as tight.

The expression like in this sentence indicates that the author wants to specify and explain the intention "These jeans are better on me" in detail."

(5) Mary is liable, huh? Huh.

There are two kinds of interpretation, one showing that the speaker is uncertain and is seeking for the confirmation of the listener, the one that the speaker is actually trying to express the opposite meaning of the literal meaning of liable, namely, the suspicion of Mary's credibility negative. The specific situation depends on the specific context, but the discourse marker huh reflects the author's subjective feelings, outside of the propositional meaning of the sentence.

Discourse markers can also indicate subjective beliefs or evaluations of language propositional meaning. They are mainly adverbs full of emotions, such as (un) fortunately, happily, regrettably, admittedly, surely, undoubtedly, obviously, and so on.

(6) Unfortunately, John has broken his leg.

Discourse markers can also be used to clearly indicate the speaker's way of speaking. They may be adverbs such as frankly, honestly, truthfully, seriously, literally, generally, strictly, or some phrases such as to blunt about it, to put it mildly, etc.. With the help of those discourse markers, the speaker can clearly show his or her own way of speaking:

(7) Honestly /Truthfully, John is a lousy driver.

(8) A woman at the library: Do you have a minute?

Librarian: Literally, one minute.

By literally, this sentence indicates that librarians are talking about an absolutely accurate "one minute", rather than a "short period of time" in the usual sense.

Discourse markers can be used to modify the speaker's wording. Communication is a dynamic process where the two communicative sides undertake exchanges on the assumption that they share same background knowledge and understand each other's existing context. Therefore, the speaker usually need to make speculation and estimation on the speaker's cognitive context and background knowledge before deciding whether to clarify or vague to clarify their point of view. At the same time, the communication is a dynamic process of changes, so the speaker should always notice whether the listener accepts and understands the information provided.

If there is certain ambiguity or misunderstanding, the speaker should promptly adjust his expressive way to meet the listener's acceptability. Therefore, the speaker may use the discourse markers with correctness such as in other words, that is to say, namely, to be exact, I mean, well, etc., to inform the other party that he or she will re-clarify or explain the information provided by the discourse.

(9) It is important not to overdo things. That is to say, it is better to do too few things at once than too many.

(10) Is the audience allowed to make any noise? I mean, is the audience allowed to express any opinion?

Therefore, discourse markers play a procedural role in the discourse, exert a impact on the meta-level of the discourse, and reflect the subjective consciousness and emotion of the speaker, so as to limit or guide the communicative partner to understand the discourse in the most appropriate way, and to achieve a successful communication. 
Thirdly, in addition to the metaphorical functions mentioned above, instrumental to the performance of the user's intention and emotion, discourse markers can also be used to shorten the psychological distance between interlocutors.

In the process of communication, the speaker will always seek for a kind of agreement or consistency so as to shorten the psychological distance between both sides. Exactly, using discourse markers can help bring the listener into the context, stimulate common emotions, and establish a cognitive context for interaction. Among those discourse markers, you know is the most typical discourse marker. On the one hand, regardless of whether or not the listener knows what he is going to utter, the speaker can use the word you know to emphasize that the following words require special attention, and remind the listener to focus on what you know guides. On the other hand, through the use of you know, the speaker can indicate the desire to establish a shared context so that the discourse is more cordial, thus shortening the psychological distance between the two sides and increasing the familiarity.

(11) A: You aren't to smoke so much, Tommy. You know, an apple a day keeps the doctor away.

Additionally, you know can also mitigate the possibility of losing face which the conflicting words may lead to.

(12) A: what? You like snow? I can't stand it, to tell you the truth.

B: Why?

A: You know, I have to drive an hour to work every day. So would you like it if you were me?

Apart from you know, other discourse markers such as as well as, we know, as you know and so on, also play the same meta-grammatical function.

(13) As we all know, when a fly lands on your forehead, you don't feel any pain whatsoever; what you feel is annoyance.

Fourthly, discourse markers also perform well in regulating interpersonal relationships. By using them, it is possible to minimize the threat of damaging the face of the listener and preserve that of the speaker own. They are usually some fuzzy words, including possibly, probably, approximately, perhaps, maybe, sort of, kind of, like, as far as I know, I suppose, I guess, I think, I believe, and some evidential markers such as reportedly, allegedly, accordingly, according to, etc..

(14) He was, you know, er, kind of, mm, sort of, er, you know, egocentric.

By using those discursive discourse markers, the speaker attempts to reduce the negative evaluation to the third party, as well as the possibility of damaging the face of the third party. Similarly, discourse markers can also reduce the possibility of damaging the face of the speaker himself or herself. When the speaker has to provide some information he or she is not fully sure, or when he or she is very eager to provide some real-time information, but the reliability and authenticity of the information is not entirely sure, he will use some discourse markers to inform the listener in advance so as to reduce the possible consequences because of his or her mistake.

(15) Reportedly /Allegedly, the royal family is in for more scandals. In short, discourse markers pragmatically function well in producing safety of the speaker's words, reducing disputes, and prompting listener beforehand, so as to reduce the possibility of ruining face of the listener and ensure the smoothness and success of the communication.

\section{Conclusion}

In summary, discourse markers in the context mainly assume procedural significance, play a textual role at the meta-level, in indicating the meta-pragmatic awareness of the user, and also perform a series of meta-pragmatic functions. They do not affect the propositional significance of the context, but guide and limit the understanding of the listener to the context, achieving the purpose of a successful communication.

This paper holds that discourse markers have the functions of constructing discourse, expressing the intention and emotion of language user, shortening the interpersonal distance, and regulating the interpersonal relationship. In the aspect of revealing the intention and emotion of language user, the meta-pragmatic function of discourse markers can also be subdivided into three kinds, according to the individual emotion of the user, the way of subjective evaluation and speech, and the modification 
of the utterance expression. Although this paper undertakes a detailed research of discourse markers, more on the meta-pragmatic functions remain to be further discussed.

\section{Acknowledgements}

Project: 16JK2187, the Scientific Research Project of Shaanxi Provincial Department of Education- The Comparative Study of Cognitive and Pragmatic Functions between English and Chinese Discourse Markers"

\section{References}

[1] Jucker, Andreas H., Yael Ziv. Discourse Markers: Introduction[C]/ /Andreas H. Jucker, Yael Ziv. Discourse Markers: Descriptions and Theory. Amsterdam /Philadelphia: John Benjamins Publishing Company, 1998.

[2] He Ziran, Ran Youping. Pragmatic Constraints of Discourse Connectives [J]. Foreign Language Teaching and Research, 1999 (3).

[3] Ran Youping. Pragmatics Review Summary of Discourse Markers [J]. Foreign Language Studies, 2000 (4).

[4] Yu Guodong, Wu Yaxin. Compliance Interpretation of Discourse Markers [J]. Journal of PLA Institute of International Studies, 2003 (1).

[5] Schiffrin, Deborah. Discourse Markers [M]. Cambridge University Press, 1987.

[6] Levinson, Stephen C.Pragmatics [M]. Foreign Language Teaching and Research Press, 2001.

[7] Redeker, Gisela. Linguistic Markers of Discourse Structure [J]. Linguistics, 1991 (29).

[8] Ran, Yongping. The Pragmatics of Discourse Markers in Conversation [D]. PhD thesis, Guangdong University of Foreign Studies, 2000.

[9] Blakemore, Diane. Semantic Constraints on Relevance [M]. Oxford: Blackwell, 1987.

[10]Ran Youping. Pragmatic Incremental Analysis of Discourse Marker You Know [J]. Journal of PLA Institute of International Studies, 2002 (4).

\section{Author's Profile}

Liu Xiuling (1980 -), female, Xi'an, Shaanxi, Master, Lecturer.

Research Direction: English Teaching and English Literature.

E-mail: 928311869@qq.com

Mailing Address: Liu Xiuling, Xi'an Science and Technology College, No.6 Science and Technology Road, Yanta District, Xi'an, Shaanxi Province

Postal Code: 710065

Tel: 13309223716 